\title{
Similarities and Differences in Human Values between Nurses in Four Countries
}

\author{
Sharon Glazer and Terry A. Beehr
}

San Fosé State University and Central Michigan University, USA

\begin{abstract}
Data on human values were collected from 1410 nurses from Hungary, Italy, the United Kingdom, and the United States. Multivariate analysis of covariance, using the mean rating of all 57 individual values, sex, marital status, and age as the covariates, showed significant differences between countries on the 10 value types. However, the variance accounted for by country on each of these values was small. A plot of the adjusted mean scores of each country on each value type, as well as Spearman rho correlations between countries on the 10 value types show that nurses tend to have similar value type profiles across countries. Because years of experience in nursing do not seem to affect these correlations, we presume that nursing attracts people with personal values that are more similar to each other than different across countries, much like the homogenization process that takes place in organizations.
\end{abstract}

KEY WORDS $\bullet$ attraction-selection-attrition $\bullet$ cross cultural psychology $\bullet$ human values $\bullet$ nurses

Nurses are probably considered universally to be in the forefront for providing ongoing care to patients, often more than doctors provide. They are responsible for constantly supervising, reporting on and maintaining patients' health, as well as making crucial care-related recommendations (Bullough and Bullough, 1982). To be a nurse, one needs to value promoting the health and welfare of others. Assuming this is likely to be universally true, it follows that nurses across various countries should have similar value profiles. However, no studies have been published in which the value profiles of nurses are examined cross culturally. Moreover, the fact that nurses 'share common backgrounds, characteristics, and orientations' (Bretz et al., 1989: 562) means that people with the values shared by nurses are probably attracted to their profession, selected by hospitals, and remain in 


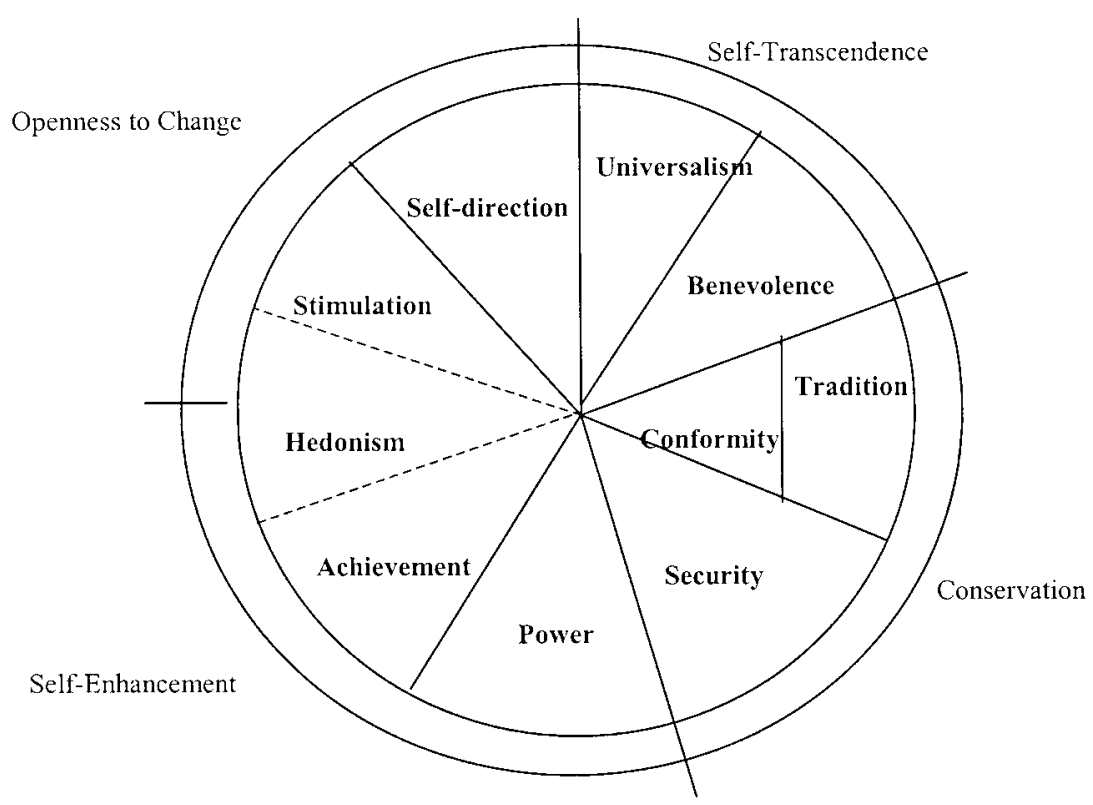

Note: With Schwartz's permission, this structure replicates the prototypical structure of the relations of value types (1994b)

Figure 1 Circular structure of the relationship between 10 adjacent and opposing value types

the hospital over time (Schneider, 1987b). Schneider summarizes research and contends that people's personalities drive their propensity toward certain career choices.

In accordance with Hofstede's (1984, 1991) recommendation for examining equivalent samples across countries, Schwartz (1992, 1994a, b) studied samples of teachers and students in over 20 countries. According to Schwartz (1994b), students embody changes in a culture and teachers carry culture and exude culture on to the pupils in a society. Schwartz was able to determine that at least eight of 10 human value types (i.e. power, achievement, hedonism, stimulation, self-direction, universalism, benevolence, tradition, conformity, and security) matched an a priori structure, in which individual values correlated to other individual values to form a circular structure of 10 adjacent and opposing value types (see Figure 1). Perhaps teachers and students across nations hold similar values (i.e. teachers may reinforce culture, while students hold ideals of what their culture should be), therefore, the value structure is similar cross culturally.

In this study, we examine if the value profiles of nurses, who have reasonably equivalent work roles but do not necessarily carry or embody the culture of a whole society, are similar across countries. In this study we will examine both the mean differences across four countries, including Hungary, Italy, the United Kingdom (UK), and the United States (US), on each of the 10 human value types, and nurses' value profiles across these countries.

\section{Human Values}

Human values are cognitive representations developed as a result of biological needs, need for social interaction, and demands for the welfare of the group (Schwartz, 1992, 
Table 1 Definitions of the 10 human values types in terms of their motivation goals and the exemplary single values that represent them

\begin{tabular}{|c|c|}
\hline Value types & Motivational goals (and exemplary values) \\
\hline Power & $\begin{array}{l}\text { Social status and prestige, control or dominance over people and resources } \\
\text { (social power, wealth, authority, preserving my public image) }\end{array}$ \\
\hline Achievement & $\begin{array}{l}\text { Personal success through demonstrating competence according to social standards } \\
\text { (ambitious, capable, influential, successful) }\end{array}$ \\
\hline Hedonism & $\begin{array}{l}\text { Pleasure and sensuous gratification for oneself (pleasure, enjoying life, } \\
\text { self-indulgent) }\end{array}$ \\
\hline Stimulation & Excitement, novelty, and challenge in life (an exciting life, a varied life, daring) \\
\hline Self-direction & $\begin{array}{l}\text { Independent thought and action-choosing, creating, exploring (freedom, creativity, } \\
\text { independent, choosing own goals, curious) }\end{array}$ \\
\hline Universalism & $\begin{array}{l}\text { Understanding, appreciation, tolerance and protection for the welfare of all people } \\
\text { and for nature (wisdom, equality, a world at peace, social justice, unity with } \\
\text { nature, a world of beauty, broadminded, protecting the environment) }\end{array}$ \\
\hline Benevolence & $\begin{array}{l}\text { Preservation and enhancement of the welfare of people with whom one is in } \\
\text { frequent personal contact (loyal, responsible, honest, helpful, forgiving) }\end{array}$ \\
\hline Tradition & $\begin{array}{l}\text { Respect, commitment and acceptance of the customs and ideas that traditional } \\
\text { culture or religion provide the self (respect for tradition, moderate, humble, } \\
\text { accepting my portion in life, devout) }\end{array}$ \\
\hline Conformity & $\begin{array}{l}\text { Restraint of actions, inclinations, and impulses likely to upset or harm others and } \\
\text { violate social expectations or norms (politeness, self-discipline, honoring of parents } \\
\text { and elders, obedient) }\end{array}$ \\
\hline Security & $\begin{array}{l}\text { Safety, harmony and stability of society, of relationships and of self (social order, } \\
\text { national security, reciprocation of favors, family security, clean) }\end{array}$ \\
\hline
\end{tabular}

Note: With Schwartz's permission (email communication 17 April 2000), this table resembles tables in his articles (e.g. Schwartz, 1996: 3, 1994b: 240, 1990: 144).

1994a; Schwartz and Sagiv, 1995). They provide desirable goals and serve as motivating principles that guide people's lives. Schwartz and colleagues proposed 10 human values including power, achievement, hedonism, stimulation, self-direction, universalism, benevolence, tradition, conformity, and security (Schwartz, 1990, 1992, 1994a, b; Schwartz and Sagiv, 1995). These values are defined and exemplary individual values are provided in Table 1.

\section{Theoretical Reasoning}

The purpose of this study is to test the degree to which nurses in different countries vary in terms of their values and to provide data by which one can compare the results of this study with future research that profiles people of various countries in matched occupations. Research by Schneider (1987b) and Schneider et al. (1995) suggests that people are attracted to, selected by, and remain with occupations and organizations in which individuals' personality characteristics (i.e. personality, attitudes and values), match those of the occupation and the organization. This concept has been labeled the ASA (Attraction-Selection-Attrition) framework. For example, Jordan et al. (1991) found people in similar occupations have similar personality types (measured using the person- 
ality measure, 16PF). Thus, through this study, we might be able to determine if the value profiles held by nurses are universal (etic) or country-specific (emic). Schneider (1987b; Schneider et al., 2000) proposes that as a result of ASA in organizations, there is homogeneity of personality.

In a study of work values in eight countries, including Hungary and the US, Elizur et al. (1991) found differences in the magnitude of importance that work values (for example, achievement at work, advancement, benefits, company, contribution to society, convenient hours of work, coworkers, esteem, feedback of work, independence, influence in the organization, etc.) had between Far Eastern and Western cultures and between communist/former communist and Western cultures. Moreover, their results indicated differences in values between those belonging to countries that appear to have similar cultural characteristics, like Germany and Holland. Thus values might facilitate understanding differences of people in different countries.

In a more recent study, Schwartz and Bardi (2001) found that the profiles of near representative national samples of adults in each of 13 countries, teachers in each of 56 nations, and college students in each of 54 nations were highly correlated (.75 or above) with the pan-cultural means of each of those sample types (minus the mean of the comparative nation) in $100 \%, 91 \%$, and $91 \%$ of the samples, respectively. However, in their study they do not correlate each individual national sample to other national samples to determine the stability of the value profiles in relation to other nations. This would be especially interesting as it would indicate whether the teacher and student samples might be attracted to, selected by, and stay with their workplace (i.e. employing organization in the case of teachers, and university education environment in the case of students) based on similarity. From their results, however, it is easy to presume that teachers and students have value types that are similar to each other because of the similar nature of their 'work', as well as similar value type patterns within their sample type because of the qualities and attributes they must possess to pursue teaching and higher education.

\section{Research Question}

Accordingly, we seek to determine if nurses from different countries hold significantly different values (see Figures 2 and 3 ) and if their value profiles are equivalent. Figure 2 illustrates approximately where the four countries fall on continua of Hofstede's four dimensions, ${ }^{1}$ based on Hofstede's (1984) Culture's Consequences. Figure 3 illustrates the hypothesized relative positions of each country on each of Schwartz's 10 values, also laid out on continua. Figure 2 facilitated the development of the hypothesized relationships in Figure 3.

\section{Method}

\section{Participants}

Nine hundred structured surveys were distributed to 900 nurses in each country and a total of 1608 were returned from nurses in Hungary, Italy, the UK, and the US, of which 1410 were used for this study. The remaining 198 either did not have complete data on values or respondents did not complete the survey as instructed. Five hundred and twenty-five surveys from four hospitals in Hungary, 376 surveys from three hospitals in Italy, 185 surveys from three hospitals in the UK, and 324 surveys from five hospitals in the US were used for this study. While most of the nurses in Hungary and USA were female $(98 \%$ and $96 \%$, respectively), it is interesting to note that in Italy about $24 \%$ of the nurses were male and in the UK 14\% of the nurses were male. However, this difference should not affect the values people hold that might affect their decision to take on a vocation of their choice. In fact, we might 


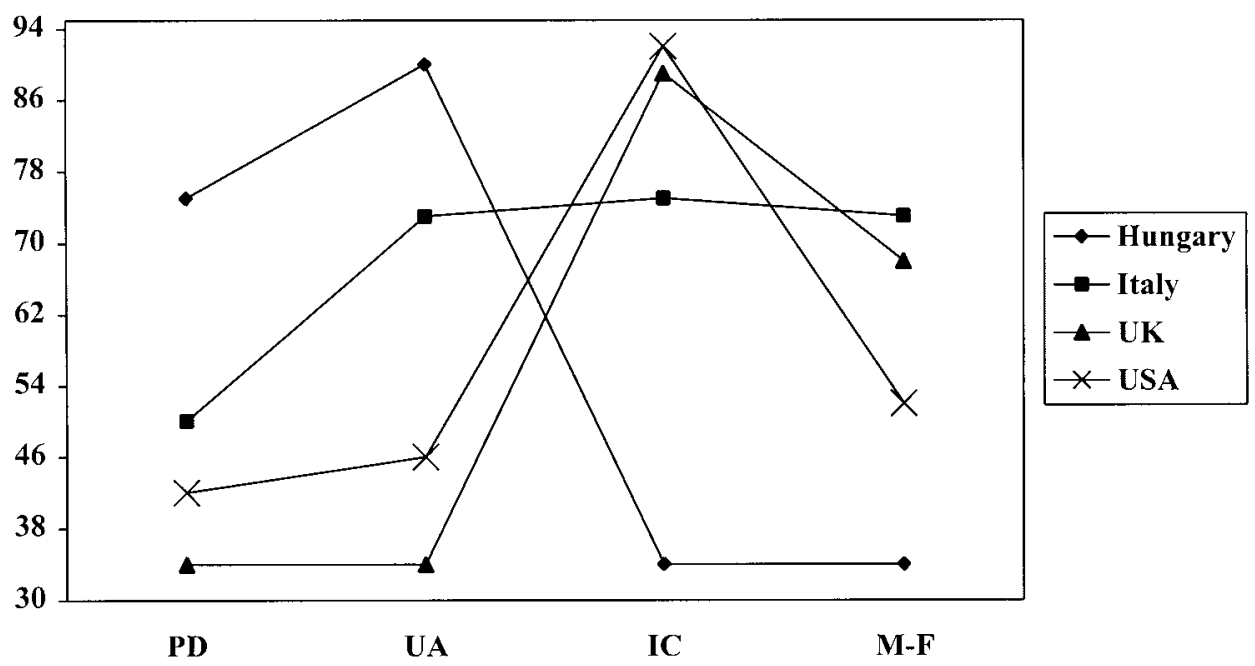

Note: Differences of values among these countries are based on Hofstede's (1984) results. However, estimates were made for Hungary on the basis of Perlaki's (1994) study. This figure is depicted in order to support the predictions for Schwartz's 10 human level value types, because nobody has done this type of research with Schwartz's values

Figure 2 Differences between Hungary, Italy, the UK and the US on values in Hofstede's four dimensions of national culture

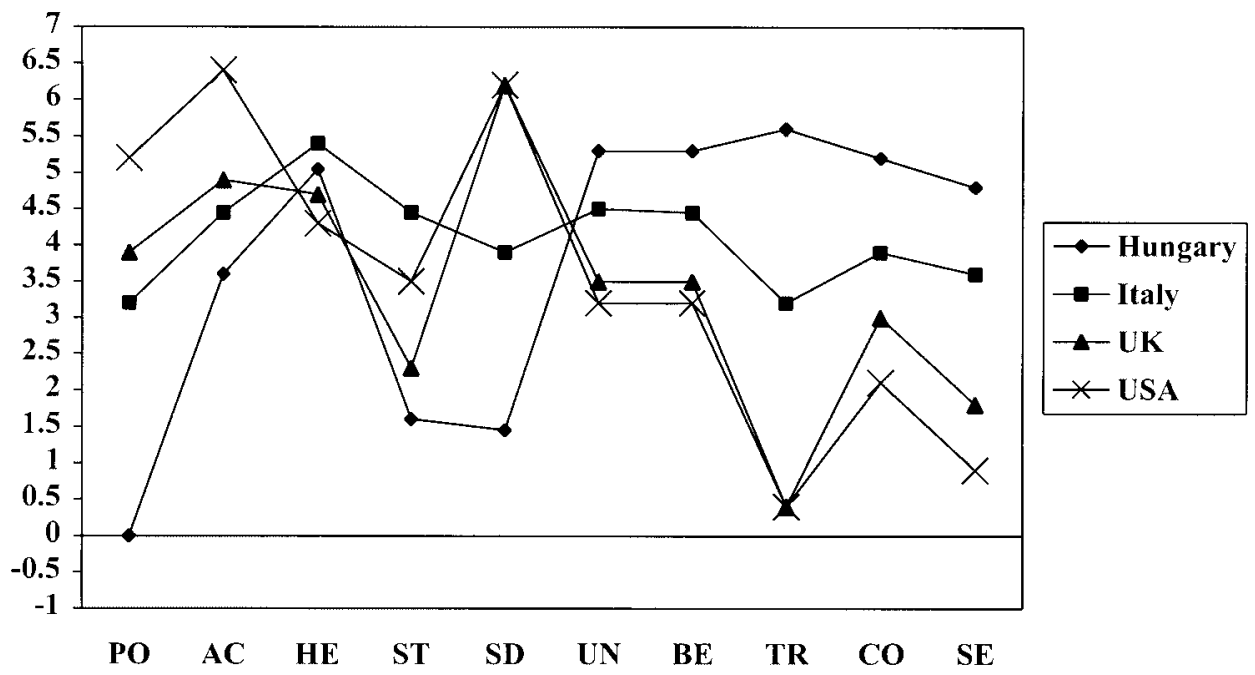

Note: $\mathrm{PO}=$ Power $; \mathrm{AC}=$ Achievement $\mathrm{HE}=$ Hedonism; $\mathrm{ST}=$ Stimulation $; \mathrm{SD}=$ Self-Direction; $\mathrm{UN}=$ Universalism; $\mathrm{BE}=$ Benevolence; $\mathrm{TR}=$ Tradition $; \mathrm{CO}=$ Conformity $\mathrm{SE}=$ Security.

Figure 3 Value profile: predicted differences between Hungary, Italy, the UK and the US on Schwartz's 10 human values 
argue that in Italy and the UK the societies might endorse people living in congruence with their values, whereas in the US and Hungary there might be a stigma attached to men working as nurses. None the less, those who have taken up nursing, whether male or female, should not vary in their life values, if there is indeed homogeneity of the values hierarchy. Rather, we would consider it a possible problem if the value priorities were not so highly correlated. If the hierarchies were heterogeneous, then sex might be a reason for the differences. However, it would be a good idea, in light of these differences, for interpretations of value differences to be made with caution.

In Hungary, nurses averaged 34 years of age, in Italy they averaged 32.7 years of age, in the UK they were roughly 34.2 years of age, and in the US nurses averaged about 41.3 years of age. The nurses had been in their occupation for approximately 13.7 years in Hungary (from newly employed to 50 years, SD $=10.10)$, 10.6 years in Italy (from 1 to 41 years, $\mathrm{SD}=7.09$ ), 13.7 years in the UK (from 0.50 to 38 years, $\mathrm{SD}=8.29$ ), and 16.7 years in the USA (from 0.70 to 40 years, $\mathrm{SD}=9.24)$. The significant age differences between nurses across countries should not affect support of the model, unless there are differences in values between high and low experience nurses (as Ostroff and Rothausen, 1997, found in their study of teachers in 29 schools, at the aggregated level of analysis). This issue is addressed in the 'Results' section regarding the present data. The main focus in this study is the nurses' similarity in value priorities. If the value profiles are similar across countries then it would be difficult to argue that age or tenure affects the similarities. In fact, it would make it easier to dispute an argument that age and tenure might change the value priorities of nurses, and we would then claim that nurses have a preconceived idea of what their occupation entails and as a result of their value priorities, they are attracted to nursing.
In Hungary $56 \%$ of the nurses were married or living with a partner, while $39 \%$ were single or divorced. In Italy $54 \%$ of the nurses were married or living with a partner and $45 \%$ were single or divorced. In the UK nurses were mostly single $(45 \%)$ or divorced (6\%), and about $46 \%$ were married or living with a partner. Finally, in the US $74 \%$ of nurses were married or living with a partner, while about $24 \%$ were single or divorced. In Italy and the UK two-thirds to four-fifths of the nurses, respectively, had no dependent children, whereas in Hungary and the US nurses with one or more children constituted one-half or two-thirds of these nursing populations, respectively. Most of the nurses across the samples worked full time.

Besides some of the significant differences in demographic data, interviews with head and chief nurses in each hospital unanimously uncovered complaints about low salaries. Nurses in Hungary, for example, earned what is equivalent to about US\$150 per month when it took about $\$ 250$ per month to live adequately at the time of data collection (in 1997). In Italy, nurses earned enough to make ends meet, but had little opportunity to save for a rainy day. Generally, UK nurses and US nurses could save a little each month, but they also felt cheated in pay in relation to others in comparable fields (in terms of level of responsibility). Generally, although the ASA model presumes that the types of reward (e.g. monetary pay) people receive in various occupations initially attract or motivate to retain people, we do not believe that this a motivator in the nursing profession in any of the countries studied. Finally, nurses performed very similar duties on the job when it came to caring for patients, including charting and completing paperwork on the patients, following the orders of doctors, cleaning the patients, administering medication, changing bedding, etc. In each country, however, they complained about having too many patients and not enough nursing staff to care for the patients. Nurses in 
the UK, the US, and Italy complained about the changes going on in the hospitals. They feel as though they cannot reach closure with patients because they are released too soon from the hospitals (see also Colburn, 1994). Many have indicated seeing the same patients come in because of worsening symptoms after being sent home and claimed that hospital policies have been changing, to the detriment of the patients.

\section{Materials}

This study was part of a larger research project in which data were collected on a variety of variables. Particular for this study are data from Schwartz's (1992) Values Scale (SVS; obtained from Schwartz in autumn 1996), which contains 57 items comprising 10 human value types. Respondents were asked to rate each individual value on the extent to which it constituted 'a guiding principle in my life' on a rating scale ranging from not important $(0)$ to of supreme importance (7) with an option of 'I am opposed to it' $(-1)$. Forty-six of the original 57 items were used to determine each of the 10 values (Schwartz, 1996). Each of the 10 value types consisted of three to eight items. The definitions of the 10 values and the exemplary 46 items (in parentheses) relating to each are in Table 1.

In accordance with Schwartz and Sagiv's suggestions (personal communication July 1998), we deleted cases when the responses of ' 3 ', '5', or ' 6 ' were given more than 34 times, the response of ' 7 ' was given more than 22 times, or no value was given to the items more than 27 times. Reducing the data this way was considered important, according to Sagiv, because with too many of the same response choices a hierarchy cannot be created. The directions instructed respondents to first anchor their responses by indicating the attribute that most guides their life with the number ' 7 ' and then the attribute that is opposed to their value system $(-1)$ in order to build the hierarchy. Furthermore, the instructions indicated to use all numbers and that people usually use very few $7 \mathrm{~s}$. Not following the directions might indicate apathy toward the survey, inability to create hierarchies (e-mail communication with Lilach Sagiv, 1 October 1998) or that a hierarchy does not exist. If there is no hierarchy, then reducing the data may be biasing the results.

\section{Trans/ation}

This portion of the questionnaire had already been translated, under the guidance of Schwartz, in the countries of interest. The translation procedure was a standard translation and back-translation. When possible, a third party reviewer verified the translations. However, prior to administering the survey for this study, the first author asked students, teachers, and lawyers to review the translations of the items. The Hungarian translators did not agree with the wording of a small number of items in the originally translated Hungarian version. Disagreements were resolved by asking a number of educators for their opinions and discussion on each of the items until consensus was reached.

\section{Procedure}

First, data were assessed for completeness, normality, homogeneity, skewness, and kurtosis. Value type scores were then averaged on the items related to the respective components. In addition, correlations, adjusted means, ${ }^{2}$ standard deviations, and reliability coefficients were examined. Next, a multivariate analysis of covariance (MANCOVA), using the multivariate general linear model procedure, with the individual's mean on the 57 individual values $(m=4.30), \operatorname{sex}(m=.90)$, marital status (single $=.29$, married $=.4877$, living with roommate $=.10$, divorced $=.09$, widowed $=.02)$ and age $(m=35.31)$ as covariates, was used to test if the adjusted mean scores on each of the value types differed significantly across countries. Also, value type profiles were illustrated for each country and then compared through a Spearman rho correlation coefficient. 


\section{Results}

Adjusted mean scores, standard deviations, correlations, and Cronbach alpha reliability coefficients are in Table 2. The variance for some of the value types appears more restricted than for others. For example, in every country the variance for hedonism and stimulation is higher and the means are lower than the variance and means for universalism and benevolence, which might result from the greater importance placed on universalism and benevolence values in the nursing profession in general.

Overall, the alphas were weaker than desirable. The reliability coefficients for the 10 value types ranged from .53 for 'security' in Italy to .81 for 'universalism' in the UK, with most of the reliability coefficients in the .60 to .80 range. The median alpha for the two English-speaking countries was .69, while it was about .61 in the other two countries, suggesting some loss in translation or transferability of the constructs cross culturally. According to Sagiv (e-mail communication 13 December 1998) the alphas were 'not much weaker than usual (if at all)'. The alpha coefficients are dependent on the items in the scale. Some single values or attributes (of the 57 single values) might be more strongly correlated with an adjacent value type than the predicted value type, in different countries, as the nature of the value types is circular (see Figure 1). For example, in the US, the single value 'successful' (expected to relate to achievement value) has a larger correlation with 'authority' (expected to relate to power value) than with 'capable' (expected to relate to achievement value).

The relations between the values fit the prototype proposed by Schwartz (1994b; Figure 1). Values that opposed each other had weaker correlations and those that were adjacent to each other had stronger correlations. For example, in the US, the correlation between the adjacent value types of benevolence and universalism was .39 , yet the correlation between opposing value types, benevolence and hedonism, was .29. Hedonism and stimulation values were adjacent and the correlation was .52. Stimulation and conformity values opposed each other and the correlation was .19.

\section{Comparison of Human Values Means between Countries}

In Figure 3, we hypothesized the value type profile for nurses in each country. In so doing, we also predicted the extent to which nurses' mean scores in each country would differ or be similar to each other on each of the 10 values. Figure 4 illustrates the actual findings. Note that the countries were placed along the continua on the basis of the adjusted mean scores (controlling for nurses' mean ratings on all 57 values, marital status, sex, and age). ${ }^{3}$ Thus each value type is compared to the average and we can see the relative importance of values to nurses in each country.

Power For the first value listed, power, nurses in Hungary had a significantly greater adjusted mean score (1.67) than nurses in the other three countries. These results completely oppose the predicted relationships (see Figure 3) between Hungary and the other three countries. The adjusted mean scores from Italy (1.01), the UK (.89), and the US (.84) did not differ significantly from each other. Returning to Figure 3, one can see that indeed the relationships between these three countries were predicted to be closer to each other than to Hungary. The variance accounted for by country in power value was $7.3 \%(F=55.83, d f=3,1331, p<.01)$, probably due to a large disparity between Hungary and the other three countries.

Achievement For the achievement value, $3.1 \%$ of variance could be accounted for by 'country' $(F=25.16, d f=3,1331, p<.01)$. US nurses were expected to have higher mean score than UK nurses, followed by 
Table 2 Means, standard deviations, correlations, and reliabilities of human values for all countries, Hungary, Italy, UK, US

\begin{tabular}{|c|c|c|c|c|c|c|c|c|c|c|c|c|}
\hline Variables & $M$ & $S D$ & 1 & 2 & 3 & 4 & 5 & 6 & 7 & 8 & 9 & 10 \\
\hline \multicolumn{13}{|c|}{ Hungary $(n=525)$} \\
\hline 1 Power & 1.72 & 1.25 & .55 & & & & & & & & & \\
\hline 2 Achievement & 2.63 & 1.16 & $.47 * *$ & .68 & & & & & & & & \\
\hline 3 Hedonism & 2.88 & 1.40 & $.33 * *$ & $.33^{* *}$ & .54 & & & & & & & \\
\hline 4 Stimulation & 1.05 & 1.46 & $.40 * *$ & $.34^{* *}$ & $.43^{* *}$ & .67 & & & & & & \\
\hline 5 Self-direction & 3.15 & 1.00 & $.35 * *$ & $.58 * *$ & $.35^{* *}$ & $.42 * *$ & .58 & & & & & \\
\hline 6 Universalism & 2.99 & .96 & $.34 * *$ & $.37 * *$ & $.19^{* *}$ & $.32 * *$ & $.53^{* *}$ & .75 & & & & \\
\hline 7 Benevolence & 3.61 & 1.09 & $.22 * *$ & $.42^{* *}$ & $.14^{* *}$ & $.09 *$ & $.41^{* *}$ & $.43^{* *}$ & .73 & & & \\
\hline 8 Tradition & 1.22 & 1.24 & $.31 * *$ & $.22^{* *}$ & $.08^{\dagger}$ & $.11 * *$ & $.20^{* * *}$ & $.48^{* * *}$ & $.36^{* *}$ & .54 & & \\
\hline 9 Conformity & 3.50 & 1.10 & $.38 * *$ & $.41^{* *}$ & .06 & $.14 * *$ & $.38 * *$ & $.54 * *$ & $.64 * *$ & $.47 * *$ & .65 & \\
\hline 10 Security & 3.75 & .92 & $.41 * *$ & $.39 * *$ & $.20 * *$ & $.18^{* *}$ & $.42^{* * *}$ & $.58 * *$ & $.43^{* *}$ & $.32 * *$ & $.58 * *$ & .57 \\
\hline \multicolumn{13}{|c|}{ Italy $(n=376)$} \\
\hline 1 Power & 0.89 & 1.33 & .61 & & & & & & & & & \\
\hline 2 Achievement & 2.54 & 1.10 & $.46^{* *}$ & .61 & & & & & & & & \\
\hline 3 Hedonism & 2.37 & 1.41 & $.40 * *$ & $.30 * *$ & .54 & & & & & & & \\
\hline 4 Stimulation & 1.66 & 1.46 & $.42 * *$ & $.39 * *$ & $.50 * *$ & .65 & & & & & & \\
\hline 5 Self-direction & 3.44 & 1.01 & $.21 * *$ & $.44^{* *}$ & $.38 * *$ & $.46^{* *}$ & .59 & & & & & \\
\hline 6 Universalism & 3.60 & .97 & .00 & $.28 * *$ & $.18 * *$ & $.23 * *$ & $.50^{* * *}$ & .74 & & & & \\
\hline 7 Benevolence & 3.85 & .97 & .03 & $.31 * *$ & $.11^{*}$ & $.09 \dagger$ & $.37 * *$ & $.45^{* *}$ & .69 & & & \\
\hline 8 Tradition & 1.70 & 1.21 & $.25 * *$ & $.24 * *$ & $.13^{*}$ & $.14 * *$ & $.18^{* * *}$ & $.35^{* *}$ & $.49 * *$ & .54 & & \\
\hline 9 Conformity & 3.64 & 1.08 & $.28 * *$ & $.35^{* *}$ & $.19 * *$ & $.15^{* *}$ & $.35^{* * *}$ & $.42^{* * *}$ & $.57 * *$ & $.53 * *$ & .64 & \\
\hline 10 Security & 3.17 & .98 & $.41 * *$ & $.36^{* * *}$ & $.30 * *$ & $.26^{* *}$ & $.35^{* * *}$ & $.38 * *$ & $.38 * *$ & $.36^{* *}$ & $.54 * *$ & .53 \\
\hline \multicolumn{13}{|c|}{$\mathrm{UK}(n=185)$} \\
\hline 1 Power & .77 & 1.22 & .68 & & & & & & & & & \\
\hline 2 Achievement & 2.84 & 1.06 & $.39 * *$ & .70 & & & & & & & & \\
\hline 3 Hedonism & 2.98 & 1.27 & $.34 * *$ & $.29 * *$ & .70 & & & & & & & \\
\hline 4 Stimulation & 2.11 & 1.36 & $.21 * *$ & $.29 * *$ & $.42 * *$ & .72 & & & & & & \\
\hline 5 Self-direction & 3.18 & .89 & $.31 * *$ & $.51 * *$ & $.38 * *$ & $.50 * *$ & .60 & & & & & \\
\hline 6 Universalism & 3.00 & 1.08 & $.15^{*}$ & $.25^{* *}$ & $.19^{*}$ & $.34 * *$ & .57 ** & .81 & & & & \\
\hline 7 Benevolence & 3.64 & .85 & $.14 \uparrow$ & $.46^{* *}$ & $.17 *$ & .10 & .37 ** & $.45^{* * *}$ & .68 & & & \\
\hline 8 Tradition & 1.45 & 1.35 & $.37 * *$ & $.34 * *$ & .05 & .02 & $.26^{* * *}$ & $.42^{* * *}$ & $.45^{* *}$ & .70 & & \\
\hline 9 Conformity & 2.79 & 1.27 & $.41 * *$ & $.42^{* *}$ & $.14 \uparrow$ & .05 & $.31^{* *}$ & $.45^{* *}$ & $.62^{* *}$ & $.71 * *$ & .74 & \\
\hline 10 Security & 2.80 & 1.15 & $.35 * *$ & $.36^{* *}$ & $.19^{* *}$ & .12 & $.37 * *$ & $.59 * *$ & $.49^{* *}$ & $.57 * *$ & $.69 * *$ & .66 \\
\hline \multicolumn{13}{|c|}{$\mathrm{US}(n=324)$} \\
\hline 1 Power & .95 & 1.11 & .63 & & & & & & & & & \\
\hline 2 Achievement & 3.06 & 1.01 & $.45^{* *}$ & .74 & & & & & & & & \\
\hline 3 Hedonism & 2.66 & 1.29 & $.46^{* *}$ & $.41 * *$ & .75 & & & & & & & \\
\hline 4 Stimulation & 1.89 & 1.26 & $.39 * *$ & $.43^{* *}$ & $.52^{* *}$ & .67 & & & & & & \\
\hline 5 Self-direction & 3.24 & .89 & $.33^{* *}$ & $.54^{* *}$ & $.42^{* *}$ & $.51^{* *}$ & .60 & & & & & \\
\hline 6 Universalism & 2.89 & .98 & $.29 * *$ & $.41^{* *}$ & $.26^{* *}$ & $.31 * *$ & $.56^{* * *}$ & .78 & & & & \\
\hline 7 Benevolence & 3.94 & .73 & $.20 * *$ & $.43^{* *}$ & $.18 * *$ & .09 & $.31 * *$ & $.39 * *$ & .65 & & & \\
\hline 8 Tradition & 2.17 & 1.13 & $.32 * *$ & $.35^{* *}$ & $.13^{*}$ & $.17^{* *}$ & $.22^{* * *}$ & $.42^{* * *}$ & $.50 * *$ & .62 & & \\
\hline 9 Conformity & 3.42 & .99 & $.34 * *$ & $.43^{* *}$ & $.26^{* *}$ & $.19 * *$ & $.35^{* * *}$ & $.46^{* * *}$ & $.60 * *$ & $.61^{* *}$ & .69 & \\
\hline 10 Security & 3.13 & .91 & $.48 * *$ & $.45^{* *}$ & $.39 * *$ & $.16^{* *}$ & $.39 * *$ & $.49 * *$ & $.41 * *$ & $.42^{* *}$ & $.57 * *$ & .57 \\
\hline
\end{tabular}

Notes: Reliability coefficients are in bold type and on the diagonal; $* * p \leq .01, * p \leq .05,{ }^{\dagger} p \leq .10$ 


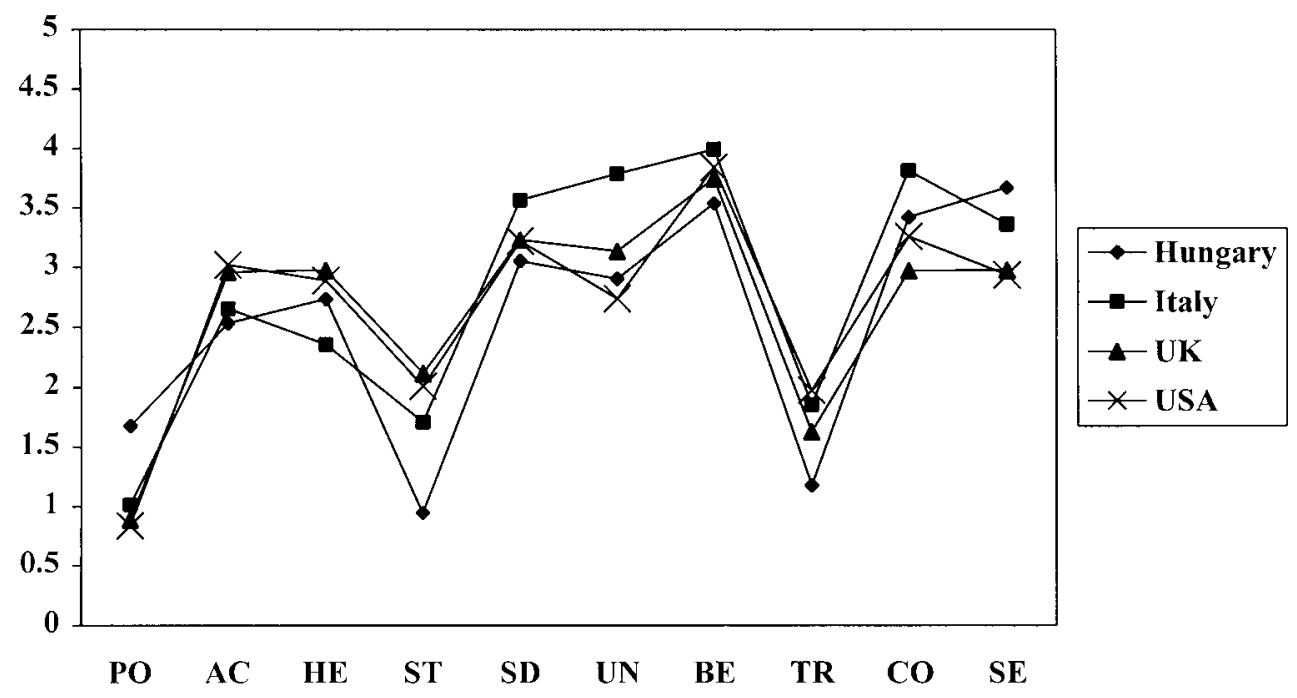

Note: $\mathrm{PO}=$ Power $; \mathrm{AC}=$ Achievement $\mathrm{HE}=$ Hedonism $; \mathrm{ST}=$ Stimulation $; \mathrm{SD}=$ Self-Direction; $\mathrm{UN}=$ Universalism; $\mathrm{BE}=$ Benevolence; $\mathrm{TR}=$ Tradition $; \mathrm{CO}=$ Conformity $; \mathrm{SE}=$ Security .

Figure 4 Value profile: actual differences between Hungary, Italy, the UK and the US on Schwartz's 10 human values

Italian, and lastly by Hungarian nurses. Results of the multivariate analysis of covariance indicated that US nurses indeed had a significantly higher adjusted mean score on achievement value (3.02) than Hungarian (2.53) and Italian (2.65) nurses. The UK nurses' adjusted mean score (2.96) on achievement value was not significantly lower than the US nurses' score. The UK nurses' adjusted mean score was significantly higher than the Italian and Hungarian nurses' mean scores, however. Further, the Italian nurses had a slightly higher, but nonsignificant adjusted mean score than the Hungarian nurses. Thus the figure was partially supported.

Hedonism Third, on valuing hedonism, 'country' accounted for $2.2 \%$ of variance $(F=15.73, d f=3,1331, p<.01)$. It was expected that Italian nurses would have a higher mean score on hedonism value than Hungarian, UK, and US nurses. In reality, the data showed that Italian nurses had a significantly lower adjusted mean score (2.36) on hedonism than any of the other countries. Adjusted mean scores were not significantly different between nurses in Hungary (2.74), the UK (2.98), and the US (2.89).

Stimulation The fourth value is stimulation for which 'country' explained $10.2 \%$ of variance $(F=70.18, d f=3,1331, p<.01)$. That Hungarian nurses would have the lowest (adjusted) mean score (.942) on stimulation value was fully supported $(p<.01)$. However, the Italian nurses had the second lowest adjusted mean score (1.71) and not the highest, and the UK had the highest adjusted mean score (2.11) and not one of the lowest. The UK adjusted mean score and the US adjusted mean score (2.01) were significantly higher than that for Italy, though the UK and the US figures were not significantly different from each other.

Self-direction On valuing self-direction, it was expected that Hungarian nurses would 
have a lower mean score than Italian nurses and that Italian nurses would have a lower mean score than UK and US nurses. Country explained $3.7 \%$ of variance on this value $(F=33.37, d f=3,1331, p<.01)$. Hungarian nurses had a significantly lower adjusted mean (3.05) than Italian (3.56), UK (3.23), and US (3.22) nurses. However, Italian nurses had a significantly higher adjusted mean score than the US and UK nurses. As expected UK and US nurses did not differ significantly from each other. These results partially support the predictions in Figure 3.

Universalism Sixth, on the value of universalism, country explained $13.4 \%$ of variance $(F=145.13, d f=3,1331, p<.01)$. Figure 3 predicted that Hungarian nurses would have a greater mean score than Italians, followed by UK and then US nurses. Each of the adjusted mean scores differed significantly from the others, but not all in the predicted direction. This hypothesis was partially supported, as Italian nurses had a significantly higher adjusted mean score (3.79) on universalism value than UK (3.14) and US (2.74) nurses. It was, however, also significantly greater than the Hungarian nurses' adjusted mean score (2.90). The UK nurses also had a significantly higher adjusted mean score than the US and Hungarian nurses.

Benevolence Next, on valuing benevolence, country explained $3.3 \%$ of variance $(F$ $=25.08, d f=3,1331, p<.01)$. One would expect nurses, in general, to score highly on valuing benevolence. Indeed, this was the case. However, it was not expected that US nurses would have a significantly higher adjusted mean score (3.84) on benevolence than nurses in Hungary (3.54). Further, the Hungarian nurses' adjusted mean score opposed our prediction and was significantly lower than the Italian (3.99) and UK (3.75) nurses' adjusted mean scores. As predicted, the Italian nurses' adjusted mean score on benevolence value was significantly greater than the UK nurses' adjusted mean score. This hypothesis was partially supported.

\section{Tradition The results of the MANCOVA} on the value of tradition were completely different from what we expected. We had expected that US and UK nurses would have lower mean scores on tradition value than Hungarian and Italian nurses. The US nurses' adjusted mean score (1.97) was significantly greater than the UK (1.63) and the Hungarian (1.18) nurses' adjusted mean scores. Furthermore, in complete opposition to what was expected, Hungarian nurses had the lowest adjusted mean score on tradition value. This score was significantly lower than the US nurses' score, the Italian nurses' score (1.85), and the UK nurses' score. These surprising results also indicated that country differences explained $6.3 \%$ of variance on tradition value $(F=50.07, d f=3,1331, p<$ $.01)$.

Conformity The ninth value examined was conformity. Hungarian nurses were expected to have the highest mean score on conformity, followed in order by the Italian, UK, and US nurses. The hypothesis was partially supported. Although all the adjusted mean scores differed significantly from each other, Italian nurses had the highest adjusted mean score (3.81) on conformity value and UK nurses had the lowest (2.97). The UK and US (3.26) nurses' adjusted mean scores were significantly lower than the Hungarian nurses' (3.42) adjusted mean score. The variance accounted for by country on conformity value was $5.2 \%(F=52.21, d f=3$, $1331, p<.01)$.

Security Finally, on valuing security, as expected, Hungarian nurses had a significantly higher adjusted mean score (3.67) than nurses in the other three countries. Also, the Italian nurses had a higher adjusted mean 
score (3.36) on security value than UK nurses (2.98) and US nurses (2.94). The UK and US nurses did not have significantly different scores. Country differences on security accounted for $8.4 \%$ of its variance $(F=$ 93.02, $d f=3,1331, p<.01)$.

\section{Testing for Similar Value Profiles}

A Spearman rho correlation between the four countries across the 10 value types was performed. That is, a data matrix was developed containing the average values of each country, with the 10 values as the cases of data and the four countries as the variables. We were then able to compute correlations between countries. Looking at differences between the correlations between different countries, the highest correlations should indicate the most similarity of value profiles between countries, and the lowest correlations should indicate the least similarity. We were surprised to find that the most similar value profiles were between the US and Italy $(\mathrm{r}=.93)$ and the US and Hungary $(\mathrm{r}=$.86). The correlations between Hungary and Italy $(\mathrm{r}=.82)$ and between the UK and Italy $(r=.80)$ were also fairly high. The least similar profiles were between the US and the UK $(r=.74)$ and the UK and Hungary $(r=$ .66). None the less, these correlations are still considerably high. Although having only 10 cases could be slightly problematic, the data in these 10 values are based on hundreds of data points, and they should therefore be relatively stable. Furthermore, power is shown not to be a problem, because the correlations are significant.

When we take into consideration the number of years nurses have been working in their profession, we found that the Spearman rho correlations between high (more than five years of experience) and low (less than or equal to five years of experience) tenure nurses within countries were high. The correlation for each of the four countries was above .93; on average across the countries it was .95 . Although it would be expected that more experienced nurses (Schneider, 1987b; Schneider et al., 2000) would be more homogeneous than less experienced nurses due to attrition, we did not find evidence of this.

\section{Discussion}

\section{Reliability}

The reliability coefficients for the nonEnglish-speaking countries were slightly lower than for the English-speaking countries. Although these differences may not be strong enough to raise serious questions regarding the translation of the surveys, it is important to note. Differences in reliability scores may also be indicative of cultural differences, response bias, or error.

\section{Differences among the Means of Values}

That some values appear to have a restriction of range (e.g. self-direction, universalism, benevolence, and security) and others do not (e.g. hedonism, stimulation, tradition, and power) might be telling of the nurses' values. They give very high scores to values that are important to them, and this causes the ceiling effect. Another interpretation is that values that do not typify nurses have greater variance. Schneider (1987b) proposed that the ASA model 'produces restriction in range the range of variance in individual differences in a setting is much less than would be expected by chance - or by the random assignment of people to settings' (p. 442). Moreover, 'a goal of formal selection procedures is to ensure that the range of person types in the setting is restricted to those who fit it' (Schneider, 1987a: 356).

In general, there were a number of significant differences in the extent to which nurses in the four countries endorsed values (see Figure 4). Similarly, Elizur et al. (1991) and Elizur (1994) found that Americans and Hungarians had differing work value struc- 
tures. For example, in this study of general life values, as in Elizur's (1994) study on work values, Hungarian nurses highly valued achievement and security. In Elizur et al.'s (1991) earlier study, Hungarians placed the least value on advancement, status, organizational influence, company, and contribution to society. Advancement value (a work value) may be akin to self-direction value (a general life value), on which Hungarian nurses averaged a lower rating (significantly different from Italy only) than nurses in the other three countries, although the rating was above the midpoint. Furthermore, Hungarians rated power value (perhaps akin to organizational influence) higher than nurses in the other three countries, but still not as very important in relation to the remaining nine value types (except stimulation and tradition values). Elizur et al. also found that Americans placed the least value on contribution to society, status, convenient hours, interaction, and work conditions. Contribution to society may be akin to universalism, which American nurses rated highly in the present study, but lower than nurses in the other three countries.

On the attributes most valued, Hungarians indicated supervisor, achievement, recognition, meaningful work, and pay. Pay might be related to security value, which Hungarian nurses rated more highly than nurses in the other three countries. However, meaningful work may be akin to stimulation value, which Hungarian nurses rated significantly lower than nurses in the other three countries and the other nine value types (see Figure 4). In Elizur's (1991) study, Americans most valued job interest, achievement, advancement, personal growth, and esteem. These work values may be related to the achievement value type for which US nurses had a higher adjusted mean score than nurses in the other three countries.

While these similarities and differences in the findings are apparent, they may not be relevant distinctions, because work values and life values may not be akin to one another. Work values are situation specific, thus indicating that the hat one wears at work, and the corresponding values, may differ from the hat one wears in non-work-related life, and the corresponding values to which one prefers to adhere. For example, we might perceive family security as a leading principle in our lives. However, when we are at work we are fulfilling that need by earning money to support our families, and thus this particular attribute is not in need of being fulfilled (as it is fulfilled). Instead, at work we may value (or desire) social recognition, thus this a guiding principle at work, but not in non-work life situations where people might be privy to social recognition from family and friends.

Although there were some significant differences between countries on various human values, the adjusted means, for the most part, appeared to show similar profiles. The high correlations between the four countries on the 10 value types suggest that the profiles of nurses' values across countries are quite similar. Values held by nurses across countries appear to be an etic, with some emic differences. This also suggests that nursing attracts and selects people who are alike in human values (Schneider, 1987b; Schneider et al., 1995), regardless of the country. Organizations tend to hire people for whom socialization to the workplace has already begun (Schneider et al., 1998), and nurses have an inherent value system that fits with the hospital organization. Therefore, nurses select themselves into hospitals more than hospitals choose the nurses. It is possible, however, that nurses working in different organizations might be less similar in their value profiles to nurses working in hospitals. As suggested by Schneider (1987b; Schneider et al., 1995, 2000), workers in the same occupation but different organization types would share some attributes, but would differ on other attributes. 'In most cases the individual's traits initially drive his or her choice 
of occupation, although not all persons successfully enter an occupation they prefer' (Schaubroeck et al., 1998: 884).

Differences were found between Hungary and the other three countries, which might be related to geographical and historical differences between the Central European country and the more westernized countries. However, these differences do not indicate a great departure from sharing a similar values profile. In fact, Hungary was highly correlated with Italy and the US across the 10 values.

A similar values profile of nurses in Hungary to those of nurses in the other countries may have arisen due to the institution of a competitive market economy in Hungary, which brings Hungary closer to the organizational structure of the other countries. Personal life values may have changed to the extent that Hungarians' values have become more westernized. Szabó (1999) reported in the Hungarian newspaper, Nepszava, on a study conducted by the Seagram Company, that a surprising trend, opposite to the 'norm', was found with regard to self-concept. Stereotypically, Szabó wrote, Hungarians are known for being pessimists, for having low self-concept, and for not striving to achieve higher self-concept. However, a surprise came from the Seagram study, which indicated that today's Hungarians, in fact, are striving to improve their selfconcept, and doing so is very important. In the Seagram study, Hungarians were the only people in Central Europe (where the study was conducted) who responded that selfconcept was an important principle guiding their lives. This may help explain why the Hungarian nurses' adjusted mean score on 'self-direction' was far off the prediction and was statistically equivalent to the adjusted mean of the US. Note that Hungary was also the second most liberal country, of the prerevolutionary Eastern bloc, after Yugoslavia (Perlaki, 1994).

According to Schwartz and Bardi (2001) the value priorities expressed by people in near representative national samples across 13 nations, and samples of teachers and students in more than 54 countries, are similar because of three major principles. These principles include promotion of and preservation of 'cooperative and supportive relations among members of primary groups' (p. 280), motivation 'to invest physical and intellectual effort to perform productive work' (p. 280), and gratification of personal and group needs, but not undermining group goals. In the present study, the top five value types (benevolence, self-direction, universalism, security, and conformity) and the ranking of the last five value types (achievement, hedonism, stimulation, tradition, and power) were similar to the top five and last five in Schwartz and Bardi's three sample types. Conformity, however, which was ranked fifth for their national sample and teacher sample, and sixth for the student sample, was second for our nursing sample. This is consistent with the idea that occupation does play a role in attracting people to jobs. The fact that teachers and students place self-direction as the second highest priority makes sense, as creativity and self-development should drive them to engage in developing their own and others' minds, but nurses must have to conform to doctors' orders and abandon selfdirection needs.

Schneider et al. (1995) would argue that organizational behavior does not influence the structure, process, or culture of that organization, but that people do. Trying to determine differences in the human values people hold in a society cannot adequately be addressed by studying one occupational group, as the people in that occupational group (i.e. nurses) hold life values that would be pertinent in making up the organization's structure, process, and culture. In other words, while society might have some influence on one's values, people within the given society who share values of an occupation would be attracted to, selected by, maintain 
membership with, and be socialized by an organization that provides the opportunity to express those life values. It can be further expected, then, that nurses probably actively choose their field of work, because the occupation and the organization fit their life values. This contention is supported in Schneider et al.'s study (1998) of managers in 142 organizations, in which they showed that personalities (based on the Myers-Briggs questionnaire) within organizations were homogeneous. It is further supported in our study, as assessing life values within an occupation-specific context provided a values profile of the specified occupation (i.e. nurses). There appear to be uniquely shared characteristics of nurses that go across geographical boundaries in terms of nurses' life values. This finding might not be a total departure from Schwartz and Bardi's (2001) findings of the teacher and student population. The high correlations between each country and the pan-cultural means might mean that teachers and students select themselves into the 'work' environment.

Through illustrating nurses' profiles in the four countries, we found that nurses possibly share similar value structures across the globe. Boski (1996) implied that nurses across countries would be consistent with the 'role-profile of nursing' (p. 32). Perhaps, as Jamal (1990) had once indicated with regard to nurses' tendencies to be primarily Type As, values held may be similar among people who have the same occupation, regardless of context. In other words, nurses might join this occupation and organization because its values are like the values of the individual joining it (Schneider et al. 1995). We showed that although value type adjusted means were significantly different in each country, the correlations between the four countries were high, and thus conclude that the values' structures (or nurses' profiles) are similar in Hungary, Italy, the UK, and the US.

Unlike Ostroff and Rothausen's (1997) study, in which tenure moderated the rela- tionship between personality and organizational climate at an aggregated level (based on three tiers for tenure across 29 schools), we did not find low and high levels of experience to affect the value profiles. Jordan et al. (1991) also found no difference between more senior people and others within the four organizations they studied. Therefore, while the ASA model would argue that as tenure increases, the values nurses hold should become increasingly homogeneous, we do not have evidence to support this in our samples. It is possible that the nurses who would not fit the nursing profession were nonresponders to the survey, because they do not feel tied to the goals of the organization. It is equally possible, however, that the field of nursing is so specialized and anyone who chooses to enter it recognizes prior to entry that the job has few extrinsic or monetary perks and that it is highly demanding (Schneider et al., 1998). These people probably saw within themselves a congruency of their own values and the values upheld by the nursing profession. As a nurse in training, one already engages in the 'dirty work' of nursing. Going into nursing, nurses know the pecking order, that is, the necessity of conforming to doctors' orders. This might be the reason also why conformity value was rated second highest across the four nursing populations (after the benevolence value), but only fifth or sixth among a national sample of adults, teachers, and students across countries (Schwartz and Bardi, 2001).

We tentatively conclude that people with certain values are attracted to nursing, because there does not appear to be much difference in the value profiles of nurses with more than and less than or equal to five years of experience.

\section{Limitations and Future Direction}

The greatest limitation of this study is the small number of countries sampled. Another limitation is having only one sample type. 
We recommend that further research be done using the SVS on nurses and other occupations similar to each other across a larger sample of countries. It would be prudent to be able to compare occupations in one industry sector to those in another. Researchers should study if nurses' value priorities are more similar to each other across countries, or if values within countries across different industries are more similar.

Schneider (1987b) wrote that when an organization wants to change, homogeneity would be its worst asset. Accordingly, in order to make the change effective, new people who embrace the values and personal characteristics of both the old as well as the new organization will help realize the organization's new goals and values. The incongruity between nurses' values and organizational changes can be seen in the US, as nurses are complaining about the changes the US healthcare system is undergoing, that is, hospitals are becoming businesses where patients are discharged before they are fully recovered (Colburn, 1994). As Schneider (1987b) pointed out, businesses that service customers first, but are forced to become more profit-centered are likely to run into personnel problems when the serviceoriented people are no longer rewarded for providing service, and possibly punished for not turning profits. The once serviceoriented organization had 'attracted, selected, and retained persons [who all have] ... service inclinations' (Schneider, 1987b: 446) and are now a poor fit with the organizational changes.

This research should serve as a steppingstone for future research profiling people's values in common occupations across countries. In effect, such research will show the commonalities people share globally. For the organizational behavioral researcher, this type of research might serve as a guide to understanding employee adjustment problems to organizational changes or counterproductive behaviors. Individuals whose values are incongruent with the occupation's value profile or with the desired organizational changes may find more difficulty in fulfilling their work roles. Thus the research might serve a second purpose of helping people learn what job sectors may best suit their values profile.

\section{Notes}

This research was supported in part by a Central Michigan University, School of Graduate Studies Dissertation Grant and in part by a Fulbright travel grant to Hungary, 1996-7.

1 Power distance relates to the relative power of supervisors over subordinates. Uncertainty avoidance focuses on individuals' lack of tolerance for uncertainty. The masculinity-femininity dimension deals with the development of group norms, roles, and leadership versus social networks and group decisions, respectively. The individualism-collectivism dimension pertains to independent personal development versus reliance on the group for survival (Hofstede, 1984).

2 Mean scores were adjusted for scale use. The scale midpoint, 3 , was subtracted from the mean of all 57 values within country (in Hungary $m=4.3857$, in Italy $m=4.1470$, in the UK $m=4.2202$, and in the US $m=$ 4.3772). The results within each country (i.e. $1.3857,1.147,1.2202$, and 1.3772, respectively) were subtracted from each of the 10 value types from each respondent's scores (within the respondent's respective country). The mean scores on each of the 10 values across all individuals within each country represent the adjusted mean score.

3 By holding marital status, sex, age, and mean rating constant, each with some missing variables, MANCOVA was performed on smaller sample sizes. The sample sizes for each country were: Hungary $=501$, Italy $=$ $348, \mathrm{UK}=176$, and $\mathrm{US}=318$.

\section{References}

Boski, P. (1996) 'Cross-cultural Psychology at the Crossroads or: Lake Victoria is not Lake Mwanza, While Cross-cultural Psychology is Not Cultural (Enough)', in H. Grad, A. Blanco and J. Georgas (eds) Key Issues in Cross- 
cultural Psychology: Selected Papers from the Twelfth International Congress of the International Association for Cross-Cultural Psychology, pp. 25-41. Lisse: Swets \& Zeitlinger.

Bretz, R.D., Jr, Ash, R.A. and Dreher, G.E. (1989) 'Do People Make the Place? An Examination of the

Attraction-Selection-Attrition Hypothesis', Personnel Psychology 42: 561-81.

Bullough, B. and Bullough, V. (1982) 'Nursing as a Profession', in P.L. Stewart and M.G. Cantor (eds) Varieties of Work, pp. 213-24. Beverly Hills: Sage.

Colburn, D. (1994) 'Nurses' Jobs Are Changing or Disappearing', Washington Post - Health Newes (22 November): 7-8.

Elizur, D. (1994) 'Gender and Work Values: A Comparative Analysis', The Fournal of Social Psychology 134: 201-12.

Elizur, D., Borg, I., Hunt, R. and Magyari Beck, I. (1991) 'The Structure of Work Values: A Cross-cultural Comparison', Fournal of Organizational Behavior 12: 21-38.

Hofstede, G. (1984) Culture's Consequences: International Differences in Work-related Values, abridged edn. Beverly Hills, CA: Sage.

Hofstede, G. (1991) Cultures and Organizations: Software of the Mind. London: McGraw-Hill.

Jamal, M. (1990) 'Relationship of Job Stress and Type A Behavior to Employees' Job Satisfaction, Organizational Commitment, Psychosomatic Health Problems, and Turnover Motivation', Human Relations 43: 727-38.

Jordan, M., Herriott, P. and Chalmers, C. (1991) 'Testing Schneider's ASA Theory', Applied Psychology: An International Review 40: 47-54.

Ostroff, C. and Rothausen, T.J. (1997) 'The

Moderating Effect of Tenure in Person-Environment Fit: A Field Study in Educational Organizations', Fournal of Occupational and Organizational Psychology 70: 173-88.

Perlaki, I. (1994) 'Organizational Development in Eastern Europe: Learning to Build Culture-specific OD Theories', Fournal of Applied Behavioral Science 30: 297-312.

Schaubroeck, J., Ganster, D.C. and Jones, J.R. (1998) 'Organization and Occupation Influences in the Attraction-Selection-Attrition Process', Fournal of Applied Psychology 83: 869-91.

Schneider, B. (1987a) ' $\mathrm{E}=\mathrm{f}(\mathrm{P}, \mathrm{B})$ : The Road to a Radical Approach to Person-Environment Fit', Journal of Vocational Behavior 31: 353-61.
Schneider, B. (1987b) 'The People Make the Place', Personnel Psychology 40: 437-53.

Schneider, B., Goldstein, H.W. and Smith, D.B. (1995) 'The ASA Framework: An Update', Personnel Psychology 48: 747-73.

Schneider, B., Smith, D.B., and Goldstein, H.W. (2000) 'Attraction-Selection-Attrition: Toward a Person-Environment Psychology of Organizations', in W.B. Walsh, K.H. Craik and R.H. Price (eds) Person-Environment Psychology: New Directions and Perspectives, 2nd edn. Mahwah, NJ: Erlbaum.

Schneider, B., Smith, D.B., Taylor, S. and Fleenor, J. (1998) 'Personality and Organizations: A Test of the Homogeneity of Personality Hypothesis', Fournal of Applied Psychology 83: 462-70.

Schwartz, S.H. (1990) 'Individualism-Collectivism: Critique and Proposed Refinements', Fournal of CrossCultural Psychology 21: 139-57.

Schwartz, S.H. (1992) 'Universals in the Content and Structure of Values: Theoretical Advances and Empirical Tests in 20 Countries', in M. Zanna (ed.) Advances in Experimental Social Psychology, Vol. 25, pp. 1-65. Orlando, FL: Academic Press.

Schwartz, S.H. (1994a) 'Beyond Individualism/Collectivism: New Cultural Dimensions of Values', in U. Kim, H.C. Triandis, C. Kagitcibasi, S. Choi and G. Yoon (eds) Individualism and Collectivism: Theory, Method, and Applications. pp. 85-119. Thousand Oaks, CA: Sage.

Schwartz, S.H. (1994b) 'Studying Human Values', in A. Bouvy, F.J.R. van de Vijver, P. Boski and P.G. Schmitz (eds) Fourneys into Cross-cultural Psychology, pp. 239-54. Amsterdam: Swets \& Zeitlinger.

Schwartz, S.H. (1996) 'Value Priorities and Behavior: Applying a Theory of Integrated Value Systems', in C. Seligman, J.M. Olson and M.P. Zanna (eds) The Psychology of Values: The Ontario Symposium, Vol. 8. Mahwah, NJ: Lawrence Erlbaum.

Schwartz, S.H. and Bardi, A. (2001) 'Value Hierarchies across Cultures: Taking a Similarities Perspective', Fournal of CrossCultural Psychology 32: 268-90.

Schwartz, S.H. and Sagiv, L. (1995) 'Identifying Culture-specifics in the Content and Structure of Values', Fournal of Cross-Cultural Psychology 26: 92-116.

Szabó, I. (1999) 'Miben küönlegesek a magyarok? [In What Are the Hungarians Special?)', Népszava (6 January): 1. 
SHARON GLAZER (to whom correspondence should be sent) is Assistant Professor, Department of Psychology, San José State University, One Washington Square, San José, CA 95192-120, USA.

[email:sglazer@email.sjsu.edu]
TERRY A. BEEHR is Professor and Director of the PhD Program in Industrial/Organizational Psychology, Central Michigan University, USA.

\section{Résumé}

\section{Similarités et différences de système de valeurs chez les infirmières dans quatre pays (Sharon Glazer et Terry A. Beehr)}

Des données sur le système de valeurs ont été collectées auprès de 1410 infirmières, en Hongrie, en Italie, au Royaume-Uni, et aux Etats-Unis. L’analyse décovariance multivariée, en utilisant les scores moyens de chacune des 57 valeurs différentes, le sexe, l'état civil, et l'âge comme covariables, a montré des différences significatives entre les pays sur les dix types de valeur. Cependant, la variance expliquée par pays sur chacune de ces valeurs est faible. Le tracé des scores moyens ajustés de chaque pays sur chaque type de valeur, mais aussi les corrélations de Spearman Rho entre les pays sur les dix types de valeur, montrent que les infirmières tendent à avoir le même type de profil de valeurs dans les différents pays. Enfin, les années d'expérience ne semblent pas non plus affecter ces corrélations. Il apparaît que le métier d'infirmière attire des personnes ayant des valeurs personnelles plus semblables entre elles que différentes selon les nationalités, à la manière du procédé d'homogénéisation qui a lieu dans les organisations.

\section{摘要}

\section{四個國家中護士的價値關的比較}

Sharon Glazer and Terry A. Beehr

研究價值關的數據來源于對匈牙利、意大利、英國和美國的 1410 名護士的調查。研究把 57 项個人的價値閣的平均値, 性 别、婚姻狀況和年龄定常常數。通過常數的比較分析顯示出各 國在十項價值形式上有明顯的不同。但每個國家在每項價値閣 上的變數卻很少。每個國家的調整平均值和斯比曼pho系數都 顯示出, 不同國家的謢士都趨于相似的價值取向。由于長年的 護士工作並没有影響系數的雙化, 所以可以推斷出, 就象 Schneide (1987)和Schneides, Goldstein, Smith (1995)所提出的 企業中發生同質性理論一樣，熱要護理工作的個人價値關在不 同國家都很相似。 